\title{
Integrating knowledge management technologies in organizational business processes: getting real time enterprises to deliver real business performance
}

Yogesh Malhotra

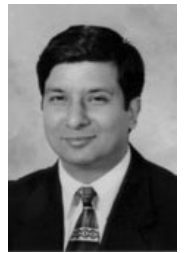

Dr Yogesh Malhotra serves on the Faculty of Management Information Systems at the Syracuse University and has taught in the executive education programs at Kellogg School of Management and Carnegie Mellon University. He is the founding chairman of BRINT Institute, LLC, the New York based internationally recognized research and advisory company. His corporate and national knowledge management advisory engagements include organizations such as Philips (The Netherlands), United Nations (New York City Headquarters), Intel Corporation (USA), National Science Foundation (USA), British Telecom (UK), Conference Board (USA), Maeil Business Newspaper and TV Network (South Korea), Ziff Davis, Government of Mexico, Government of The Netherlands, and Federal Government of the USA. He can be contacted at: www.yogeshmalhotra.com

Constructive comments offered by the special issue Editor Eric Tsui and the two anonymous reviewers are gratefully acknowledged.

\begin{abstract}
Purpose - To provide executives and scholars with pragmatic understanding about integrating knowledge management strategy and technologies in business processes for successful performance.

Design/methodology/approach - A comprehensive review of theory, research, and practices on knowledge management develops a framework that contrasts existing technology-push models with proposed strategy-pull models. The framework explains how the "critical gaps" between technology inputs, related knowledge processes, and business performance outcomes can be bridged for the two types of models. Illustrative case studies of real-time enterprise (RTE) business model designs for both successful and unsuccessful companies are used to provide real world understanding of the proposed framework.

Findings - Suggests superiority of strategy-pull models made feasible by new "plug-and-play" information and communication technologies over the traditional technology-push models. Critical importance of strategic execution in guiding the design of enterprise knowledge processes as well as selection and implementation of related technologies is explained.

Research limitations/implications - Given the limited number of cases, the framework is based on real world evidence about companies most popularized for real time technologies by some technology analysts. This limited sample helps understand the caveats in analysts' advice by highlighting the critical importance of strategic execution over selection of specific technologies. However, the framework needs to be tested with multiple enterprises to determine the contingencies that may be relevant to its application.

Originality/value - The first comprehensive analysis relating knowledge management and its integration into enterprise business processes for achieving agility and adaptability often associated with the "real time enterprise" business models. It constitutes critical knowledge for organizations that must depend on information and communication technologies for increasing strategic agility and adaptability.
\end{abstract}

Keywords Knowledge management, Real time scheduling, Business performance,

Return on investment

Paper type Research paper

\section{Introduction}

Technologists never evangelize without a disclaimer: "Technology is just an enabler." True enough - and the disclaimer discloses part of the problem: enabling what? One flaw in knowledge management is that it often neglects to ask what knowledge to manage and toward what end. Knowledge management activities are all over the map: building databases, measuring intellectual capital, establishing corporate libraries, building intranets, sharing best practices, installing groupware, leading training programs, leading cultural change, fostering collaboration, creating virtual organizations - all of these are knowledge management, and every functional and staff leader can lay claim to it. But no one claims the big question: why? (Tom Stewart in The Case Against Knowledge Management, Business 2.0, February 2002).

The recent summit on knowledge management (KM) at the pre-eminent ASIST conference opened on a rather upbeat note. The preface noted that KM has evolved into a mature reality from what was merely a blip on the "good idea" radar only a few years ago. Growing 
pervasiveness of $\mathrm{KM}$ in worldwide industries, organizations, and institutions marks a watershed event for what was called a fad just a few years ago. KM has become embedded in the policy, strategy, and implementation processes of worldwide corporations, governments, and institutions. Doubling in size from 2001, the global KM market has been projected to reach US\$8.8 billion during this year. Likewise, the market for KM business application capabilities such as CRM (Malhotra, 2004a) is expected to grow to $\$ 148$ billion by the next year. $\mathrm{KM}$ is also expected to help save $\$ 31$ billion in annual re-invention costs at Fortune 500 companies. The broader application context of KM, which includes learning, education, and training industries, offers similarly sanguine forecasts. Annual public K-12 education is estimated at \$373 billion dollars in US alone, with higher education accounting for $\$ 247$ billion dollars. In addition, the annual corporate and government training expenditures in the US alone are projected at over $\$ 70$ billion dollars.

One can see the impact of knowledge management everywhere but in the KM technology-performance statistics (Malhotra, 2003). This seems like a contradiction of sorts given the pervasive role of information and communication technologies in most KM applications. Some industry estimates have pegged the failure rate of technology implementations for business process reengineering efforts at 70 percent. Recent industry data suggest a similar failure rate of KM related technology implementations and related applications (Darrell et al., 2002). Significant failure rates persist despite tremendous improvements in sophistication of technologies and major gains in related price-performance ratios. At the time of writing, technology executives are facing a renewed credibility crisis resulting from cost overruns and performance problems for major implementations (Anthes and Hoffman, 2003). In a recent survey by Hackett Group, 45 percent ClOs attribute these problems to technology implementations being too slow and too expensive. Interestingly, just a few months ago, some research studies had found negative correlation between tech investments and business performance (Alinean, 2002; Hoffman, 2002). Financial performance analysis of 7,500 companies relative to their IT spending and individual surveys of more than 200 companies had revealed that:

- companies with best-performing IT investments are often most frugal IT spenders;

- top 25 performers invested 0.8 percent of their revenues on IT in contrast to overall average of 3.7 percent; and

- highest IT spenders typically under-performed by up to 50 percent compared with best-in-class peers.

Based upon multi-year macroeconomic analysis of hundreds of corporations, Strassmann (1997) had emphasized that it is not computers but what people do with them that matters. He had further emphasized the role of users' motivation and commitment in IT performance[1]. Relatively recent research on implementation of enterprise level KMS (Malhotra, 1998a; Malhotra and Galletta, 1999; Malhotra and Galletta, 2003; Malhotra and Galletta, n.d. a; Malhotra and Galletta, n.d. b) has found empirical support for such socio-psychological factors in determining IT and KMS performance. An earlier study by Forrester Research had similarly determined that the top-performing companies in terms of revenue, return on assets, and cash-flow growth spend less on IT on average than other companies. Surprisingly, some of these high performance "benchmark" companies have the lowest tech investments and are recognized laggards in adoption of leading-edge 


\section{"Despite increasing sophistication of KM technologies, we are observing increasing failures of KM technology implementations."}

technologies. Research on best performing US companies over the last 30 years (Collins, 2001) has discovered similar "findings". The above findings may seem contrarian given persistent and long-term depiction of technology as enabler of business productivity (cf. Brynjolfsson, 1993; Brynjolfsson and Hitt, 1996; Brynjolfsson and Hitt, 1998; Kraemer, 2001).

Despite increasing sophistication of KM technologies, we are observing increasing failures of KM technology implementations (Malhotra, 2004b). The following sections discuss how such failures result from the knowledge gaps between technology inputs, knowledge processes, and business performance. Drawing upon theory, prior research, and industry case studies, we also explain why some companies that spend less on technology and are not leaders in adoption of most hyped RTE technologies succeed where others fail. The specific focus of our analyses is on the application of KM technologies in organizational business processes for enabling real time enterprise business models. The RTE enterprise is considered the epitome of the agile adaptive and responsive enterprise capable of anticipating surprise; hence our attempt to reconcile its sense making and information processing capabilities is all the more interesting. However, our theoretical generalizations and their practical implications are relevant to IT and KM systems in most enterprises traversing through changing business environments.

\section{Disconnects between disruptive information technologies and relevant knowledge}

Organizations have managed knowledge for centuries. However, the popular interest in digitizing business enterprises and knowledge embedded in business processes dates back to 1993[2]. Around this time, the Business Week cover story on virtual corporations (Byrne, 1993) heralded the emergence of the new model of the business enterprise. The new enterprise business model was expected to make it possible to deliver anything, anytime, and, anywhere to potential customers. It would be realized by digitally connecting distributed capabilities across organizational and geographical boundaries. Subsequently, the vision of the virtual, distributed, and digitized business enterprise became a pragmatic reality with the mainstream adoption of the internet and web. Incidentally, the distribution and digitization of enterprise business processes was expedited by the evolution of technology architectures beyond mainframe to client-server to the internet and the web and more recently to web services. Simultaneously, the software and hardware paradigms have evolved to integrated hosted services and more recently to utility computing and on demand computing (Greenemeier, 2003a, b; Hapgood, 2003; Sawhney, 2003; Thickins, 2003) models. Organizations with legacy enterprise business applications trying to catch up with the business technology shifts have ended up with disparate islands of diverse technologies.

\section{Decreasing utility of the technology-push model}

Management and coordination of diverse technology architectures, data architectures, and system architectures poses obvious knowledge management challenges (Malhotra, 1996; Malhotra, 2001a; Malhotra, 2004b). Such challenges result from the need for integrating diverse technologies, computer programs, and data sources across internal business processes. These challenges are compounded manifold by the concurrent need for simultaneously adapting enterprise architectures to keep up with changes in the external business environment. Often such adaptation requires upgrades and changes in existing technologies or their replacement with newer technologies. Going business enterprises 
often have too much (unprocessed) data and (processed) information and too many technologies. However, for most high-risk and high-return strategic decisions, timely information is often unavailable as more and more of such information is external in nature (Drucker, 1994; Malhotra, 1993; Terreberry, 1968; Emery and Trist, 1965). Also, internal information may often be hopelessly out of date with respect to evolving strategic needs. Cycles of re-structuring and downsizing often leave little time or attention to ensure that the dominant business logic is kept in tune with changing competitive and strategic needs.

As a result, most organizations of any size and scope are caught in a double whammy of sorts. They do not know what they know. In simple terms, they have incomplete knowledge of explicit and tacit data, information, and decision models available within the enterprise. Also, their very survival may sometimes hinge on obsolescing what they know (see for instance, Yuva, 2002; Malhotra, 2004b; Malhotra, 2002c). In other words, often they may not know if the available data, information, and decision models are indeed up to speed with the radical discontinuous changes in the business environment (Arthur, 1996; Malhotra, 2000a; Nadler and Shaw, 1995). In this model, incomplete and often outdated data, information, and decision models drive the realization of the strategic execution, but with diminishing effectiveness. The model may include reactive and corrective feedback loops. The logic for processing specific information and respective responses are all pre-programmed, pre-configured, and pre-determined. The mechanistic information-processing orientation of the model generally does not encourage diverse interpretations of information or possibility of multiple responses to same information. As depicted in Figure 1, this model of $\mathrm{KM}$ is often driven by technological systems that are out-of-alignment with strategic execution and may be characterized as the technology-push model. This model has served the needs of business performance given more manageable volumes of information and lesser variety of systems within relatively certain business environment. However, with recent unprecedented growth in volumes of data and information, the continuously evolving variety of technology architectures, and the radically changing business environment, this model has outlasted its utility. The limitations of the technology-push model are evident in the following depiction of IT architectures as described in Information Week by LeClaire and Cooper (2000):

The infrastructure issue is affecting all businesses ... E-business is forcing companies to rearchitect all or part of their IT infrastructures - and to do it quickly. For better or worse, the classic timeline of total business-process reengineering - where consultants are brought in, models are drawn up, and plans are implemented gradually over months or years - just isn't fast enough to give companies the e-commerce-ready IT infrastructures they need ... Many companies can't afford to go back to the drawing board and completely rearchitect critical

\section{Figure 1 How ICT systems drive and constrain strategic execution}

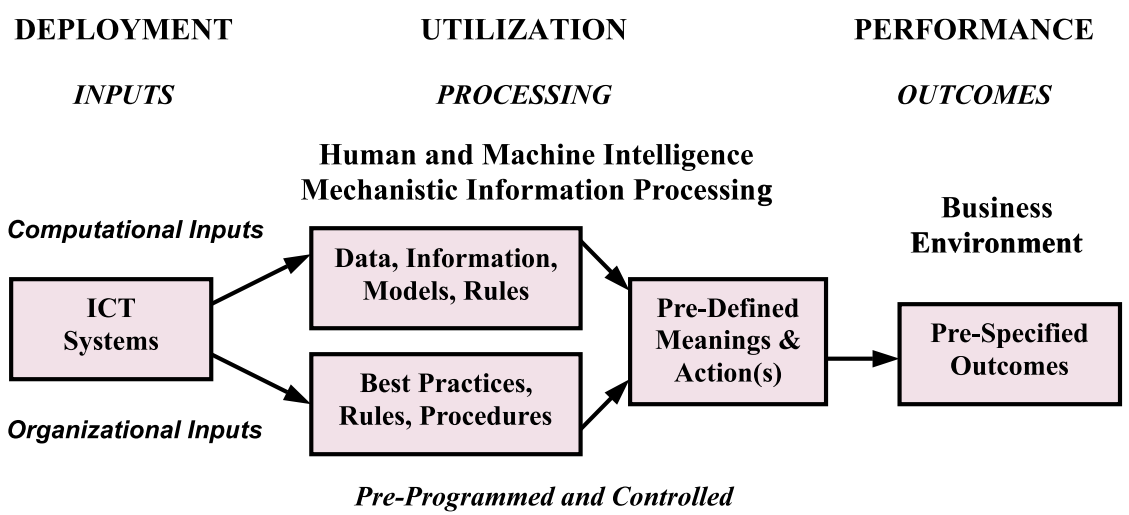

\section{TECHNOLOGY-PUSH MODEL OF KM}




\title{
"The gap between IT and business performance has grown with the shifting focus of business technology strategists and executives."
}

\begin{abstract}
systems such as order fulfillment and product databases from the bottom up because they greatly depend on existing infrastructure. More often, business-process reengineering is done reactively. Beyond its disruptive effect on business operations, most IT managers and executives don't feel there's enough time to take a holistic approach to the problem, so they attack tactical issues one-by-one. Many companies tackle a specific problem with a definitive solution rather than completely overhaul the workflow that spans from a customer query to online catalogs to order processing.
\end{abstract}

\section{Strategic execution: the real driver of business performance}

The gap between IT and business performance has grown with the shifting focus of business technology strategists and executives. Over the past two decades, their emphasis has shifted from IT (Porter and Millar, 1985; Hammer 1990) to information (Evans and Wurster, 2002; Rayport and Sviokla, 1995; Hopper, 1990; Huber, 1993; Malhotra, 1995) to knowledge (Holsapple and Singh, 2001; Holsapple, 2002; Koenig and Srikantaiah, 2000a; Malhotra, 2004b; Malhotra, 2000b; Malhotra, 1998c) as the lever of competitive advantage. At the time of the writing, technology sales forecasts are gloomy because of the distrust of business executives who were previously oversold on the capabilities of technologies to address real business threats and opportunities. This follows on the heels of the on-and-off love-hate relationship of the old economy enterprises and media analysts with the new economy business models over the past decade. We first saw unwarranted wholesale adulation and subsequently wholesale decimation of technology stocks. All the while, many industry executives and most analysts have incorrectly presumed or pitched technology as the primary enabler of business performance (Collins, 2001; Schrage, 2002)[3].

The findings from the research (Collins, 2001) on best performing companies over the last three decades are summarized in Table I. These findings are presented in terms of the inputs-processing-outcomes framework used for contrasting the technology-push model with the strategy-pull model of KM implementation[4]. Subsequent discussion will further explain the relative advantages of the latter in terms of strategic execution and business performance. Given latest advances in web services, the strategic framework of KM discussed here presents a viable alternative for delivering business performance as well as enterprise agility and adaptability (Strassmann, 2003).

\section{Will the real knowledge management please stand up?}

The technology evangelists, criticized by Stewart (2000), have endowed the KM technologies with intrinsic and infallible capability of getting the right information to the right person at the right time. Similar critiques (cf. Malhotra, 2000a; Hildebrand, 1999) have further unraveled and explained the "myths" associated such proclamations made by the technology evangelists. Specifically, it has been underscored that in wicked business environments (Churchman, 1971; Malhotra, 1997) characterized by radical discontinuous change (Malhotra, 2000a; Malhotra, 2002b), the deterministic and reductionist logic (Odom and Starns, 2003) of the evangelists does not hold. Incidentally, most high potential business opportunities and threats are often embedded within such environments (Arthur, 1996; Malhotra, 2000c; Malhotra, 2000d). Such environments are characterized by fundamental and ongoing changes in technologies as well as the strategic composition of market forces. Increasing failures rates of KM technologies often result from their rapid obsolescence given changing business needs and technology architectures. Popular re-labeling by vendors of many information technologies as KM technologies has not helped the situation. Skeptics of 
Lessons learned from some of the most successful business enterprises that distinguished themselves by making the leap from "good to great" (Collins, 2001)

Lessons about outcomes: strategic execution, the primary enabler

(1) How a company reacts to technological change is a good indicator of its inner drive for greatness versus mediocrity. Great companies respond with thoughtfulness and creativity, driven by a compulsion to turn unrealized potential into results; mediocre companies react and lurch about, motivated by fear of being left behind

(2) Any decision about technology needs to fit directly with three key non-technological questions: What are you deeply passionate about? What can you be the best in the world at? What drives your economic engine? If a technology does not fit squarely within the execution of these three core business issues, the good-to-great companies ignore all hype and fear and just go about their business with a remarkable degree of equanimity

(3) The good-to-great companies understood that doing what you are good at will only make you good; focusing solely on what you can potentially do better than any other organization is the only path to greatness

Lessons about processing: how strategic execution drives technology utilization

(1) Thoughtless reliance on technology is a liability, not an asset. When used right - when linked to a simple, clear, and coherent concept rooted in deep understanding - technology is an essential driver in accelerating forward momentum. But when used wrongly - when grasped as an easy solution, without deep understanding of how it links to a clear and coherent concept - technology simply accelerates your own self-created demise

(2) No evidence was found that good-to-great companies had more or better information than the comparison companies. In fact both sets of companies had identical access to good information. The key, then, lies not in better information, but in turning information into information that cannot be ignored

(3) 80 percent of the good-to-great executives did not even mention technology as one of the top five factors in their transition from good-to-great. Certainly not because they ignored technology: they were technologically sophisticated and vastly superior to their comparisons

(4) A number of the good-to-great companies received extensive media coverage and awards for their pioneering use of technology. Yet the executives hardly talked about technology. It is as if the media articles and the executives were discussing two totally different sets of companies!

Lessons about technology inputs: how strategic execution drives technology deployment

(1) Technology-induced change is nothing new. The real question is not What is the role of technology? Rather, the real question is How do good-to-great organizations think differently about technology?

(2) It was never technology per se, but the pioneering application of carefully selected technologies. Every good-to-great company became a pioneer in the application of technology, but the technologies themselves varied greatly

(3) When used right, technology becomes an accelerator of momentum, not a creator of it. The good-to-great companies never began their transitions with pioneering technology, for the simple reason that you cannot make good use of technology until you know which technologies are relevant

(4) You could have taken the exact same leading-edge technologies pioneered at the good-to-great companies and handed them to their direct comparisons for free, and the comparisons still would have failed to produce anywhere near the same results

technology have observed that real knowledge is created and applied in the processes of socialization, externalization, combination, and internalization (Nonaka and Takeuchi, 1995) and outside the realm of KM technologies. Practitioners' inability to harness relevant knowledge despite KM technologies and offices of the CKOs caused the backlash and KM was temporarily branded as a fad. Scholarly research on latest information systems and technologies, or lack thereof, has further contributed to the confusion between data management, information management, and knowledge management. 


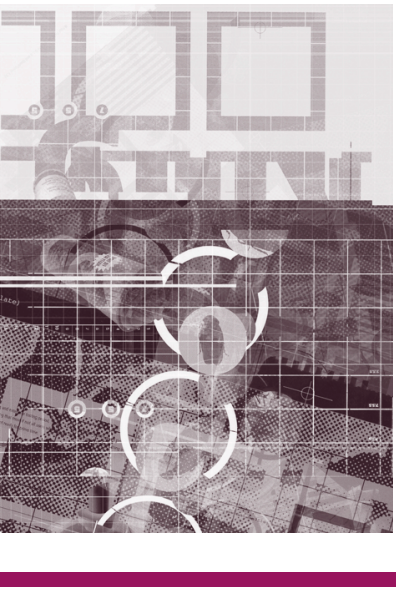

Recent reviews of theory and research on information systems and KM (Alavi and Leidner, 2001; Schultze and Leidner, 2002) seem to confirm Stewart's (2000) observation about the key flaw of knowledge management:

Knowledge management activities are all over the map ... But no one claims the big question: why?

Hence, it is critical that a robust distinction between technology management and knowledge management should be based on theoretical arguments that have been tested empirically in the "real world messes" (Ackoff, 1979) and the "world of re-everything" (Arthur, 1996). We are observing diminishing credibility of information technologists (Anthes and Hoffman, 2003; Hoffman, 2003; Carr, 2003). A key reason for this is an urgent need for understanding how technologies, people, and processes together influence business performance (Murphy, 2003). Explicit focus on strategic execution as the driver of technology configurations in the strategy-pull KM framework reconciles many of the above problems. The evolving paradigm of technology architectures to on demand plug-and-play inter-enterprise business process networks (Levitt, 2001) is expected to facilitate future realization of KM value networks. Growing popularity of the web services architecture (based upon XML, UDDI, SOAP, WSDL) is expected to support the realization of real-time deployment of business performance driven systems based upon the proposed model (Kirkpatrick, 2003; Zetie, 2003; Murphy, 2003).

The technology-push model is attributable for the inputs - and processing - driven KM implementations with emphasis on pushing data, information, and decisions. In contrast, the strategy-pull model recognizes that getting pre-programmed information to pre-determined persons at the pre-specified time may not by itself ensure business performance. Even if pre-programmed information does not become out-dated, the recipient's attention and engagement with that information is at least equally important. Equally important is the reflective capability of the recipient to determine if novel interpretation of the information is necessary or if consideration of novel responses is in order given external changes in the business environment. The technology-push model relies upon single-loop automated and unquestioned automatic and pre-programmed response to received stimulus. In contrast, the strategy-pull model has built in double-loop process that can enable a true sense-and-respond paradigm of KM[5]. The focus of the technology-push model is on mechanistic information processing while the strategy-pull model facilitates organic sense making (Malhotra, 2001b). The distinctive models of knowledge management have been embedded in KM implementations of most organizations since KM became fashionable. For instance, the contrast between the models can be illustrated be comparing the fundamental paradigm of KM guiding the two organizations, a US global communications company and a US global pharmaceutical firm. The telecommunications company adopted the mechanistic information- and processing-driven paradigm of KM (Stewart and Kaufman, 1995):

What's important is to find useful knowledge, bottle it, and pass it around.

In contrast, given their emphasis on insights, innovation, and creativity, the pharmaceutical company adopted the organic sense-making model of KM (Dragoon, 1995, p. 52):

There's a great big river of data out there. Rather than building dams to try and bottle it all up into discrete little entities, we just give people canoes and compasses.

The former model enforces top-down compliance and control through delivery of institutionalized information and decision models. In contrast, the latter model encourages discovery and exploration for questioning given assumptions and surfacing new insights (Nonaka and Takeuchi, 1995).

\section{Real time strategic execution: the real enabler of the RTE}

The issues of technology deployment, technology utilization, and business performance need to be addressed together to ensure that technology can deliver upon the promise of business performance. Interestingly, most implementations of KM systems motivated by the technology-push model have inadvertently treated business performance as a residual: what remains after issues of technology deployment and utilization are addressed[6]. This 
perhaps explains the current malaise of IT executives and IT management in not being able to connect with business performance needs (Hoffman, 2003). A sense-and-respond KM system that can respond in real time would need to consider the holistic and collective effect of:

- real-time deployment in terms of tech and human infrastructure (inputs);

- real-time utilization in terms of what is done about or with information (processing); and

- real-time performance in terms of how it delivers business performance (outcomes).

Deployment of intranets, extranets, or, groupware cannot of itself deliver business performance. These technologies would need to be adopted and appropriated by the human users, integrated within their respective work-contexts, and effectively utilized while being driven by the performance outcomes of the enterprise. To deliver real-time response, business performance would need to drive the information needs and technology deployment needs. This is in congruence with the knowledge management logic of the top performing companies discussed earlier. These enterprises may not have created the buzz about the latest technologies. However, it is unquestionable that these best performing organizations harnessed organizational and inter-organizational knowledge embedded in business processes most effectively to deliver top-of-the-line results. The old model of technology deployment spanning months or often years often resulted in increasing misalignment with changing business needs. Interestingly, the proposed model turns the technology-push model on its head. The strategy-pull model illustrated in Figure 2 treats business performance not as the residual but as the prime driver of information utilization as well as IT-deployment.

The contrast between the inputs-processing-output paradigms of KM implementations is further explained in the following section to bridge the existing gaps in $\mathrm{KM}$ research and practice.

\section{Gaps in KM implementation research and practice}

The "knowledge application gap" that is characteristic of the inputs- and processing-driven technology-push model have also been the subject of criticism in scholarly research on KM (Alavi and Leidner, 2001; Zack, 2001). However, these gaps seem to persist across most of theoretical research and industry practices related to information systems and knowledge management as shown in Table II. As discussed in Malhotra (2000a), such gaps have persisted over the past decade despite advances in understanding of $\mathrm{KM}$ and sophistication of technology architectures.

\section{Figure 2 Strategic execution - the primary enabler of the RTE business model}

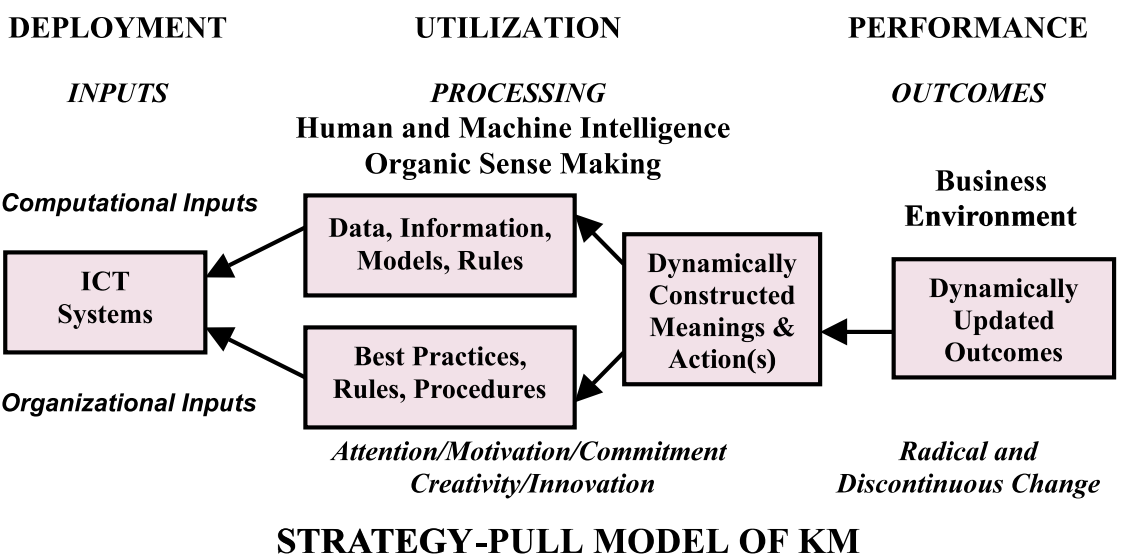

PAGE 14 | JOURNAL OF KNOWLEDGE MANAGEMENT| VOL. 9 NO. 12005 
Table II Driving KM with business performance from inputs- and processing-driven KM to outcomes-driven $\mathrm{KM}$

Additional theoretical and applied definitions of KM are discussed in Malhotra (2000a)

Technology-push models of KM

(Depicted in Figure 1)

Inputs-driven paradigm of $K M$

"Knowledge management systems (KMS) refer to a class of information systems applied to managing organizational knowledge. That is, they are IT-based systems developed to support and enhance the organizational processes of knowledge creation, storage/retrieval, transfer, and application" (Alavi and Leidner, 2001)

"Knowledge management is the generation, representation, storage, transfer, transformation, application, embedding, and protecting of organizational knowledge" (Schultze and Leidner, 2002) "For the most part, knowledge management efforts have focused on developing new applications of information technology to support the capture, storage, retrieval, and distribution of explicit knowledge" (Grover and Davenport, 2001)

"Knowledge has the highest value, the most human contribution, the greatest relevance to decisions and actions, and the greatest dependence on a specific situation or context. It is also the most difficult of content types to manage, because it originates and is applied in the minds of human beings"

(Grover and Davenport, 2001)

"Knowledge management uses complex networks of information technology to leverage human capital. The integration of user-friendly electronic formats facilitates inter-employee and customer communication; a central requirement for successful KM programs"' (eMarketer, 2001)

"In companies that sell relatively standardized products that fill common needs, knowledge is carefully codified and stored in databases, where it can be accessed and used - over and over again - by anyone in the organization" (Hansen and Nohria, 1999)

\section{Processing-driven paradigm of KM}

"KM entails helping people share and put knowledge into action by creating access, context, infrastructure, and simultaneously reducing learning cycles" (Massey et al., 2001)

"Knowledge management is a function of the generation and dissemination of information, developing a shared understanding of the information, filtering shared understandings into degrees of potential value, and storing valuable knowledge within the confines of an accessible organizational mechanism" (CFP for Decision Sciences special issue on Knowledge Management, 2002)

"In companies that provide highly customized solutions to unique problems, knowledge is shared mainly through person-to-person contacts; the chief purpose of computers is to help people communicate" (Hansen and Nohria, 1999)

\section{Strategy-pull model of KM \\ (Depicted in Figure 2)}

Outcomes-driven paradigm of KM

"Knowledge Management refers to the critical issues of organizational adaptation, survival and competence against discontinuous environmental change. Essentially it embodies organizational processes that seek synergistic combination of data and information-processing capacity of information technologies, and the creative and innovative capacity of human beings" (Malhotra, 1998b)

The sample of "definitions" of KM listed in Table II is not exhaustive but illustrative. However, it gets the point across about the missing link between KM and business performance in research and practice literatures. Despite lack of agreement on what is $\mathrm{KM}$, most such interpretations share common emphasis on the inputs- and processing-driven technology-push model. Review of most such "definitions" also leaves one begging for a response to Stewart's pointed question to technologists' evangelism about KM: "why?" In contrast, the strategy-pull model with its outcomes-driven paradigm seems to offer a more meaningful and pragmatic foundation for KM. At least as far as real world outcomes are concerned, this paradigm measures up to the expectations about KM policy and its implementation in worldwide organizations[7]. Better understanding of the gaps that we are trying to reconcile is possible by appreciating 


\section{"Increasing failures rates of KM technologies often result from their rapid obsolescence given changing business needs and technology architectures."}

the contrast between the three paradigms of KM implementation that have characterized the technology-push and strategy-pull models of KM depicted in Figures 1 and 2. This contrast is explained in terms of their primary and differential focus on the inputs, processing, and outcomes.

The inputs-driven paradigm considers information technology and KM as synonymous. The inputs-driven paradigm with its primary focuses on technologies such as digital repositories, databases, intranets, and, groupware systems has been the mainstay of many KM implementation projects. Specific choices of technologies drive the KM equation with primary emphasis on getting the right information technologies in place. However, the availability of such technologies does not ensure that they positively influence business performance. For instance, installing a collaborative community platform may neither result in collaboration nor community (Barth, 2000; Charles, 2002; Verton, 2002). The practitioners influenced by this paradigm need to review the "lessons about technology inputs" listed earlier in Table I.

The processing-driven paradigm of KM has its focus on best practices, training and learning programs, cultural change, collaboration, and virtual organizations. This paradigm considers KM primarily as means of processing information for various business activities. Most proponents of RTE belong to this paradigm given their credo of getting the right information to the right person at the right time. Specific focus is on the activities associated with information processing such as process redesign, workflow optimization, or automation of manual processes. Emphasis on processes ensures that relevant technologies are adopted and possibly utilized in service of the processes. However, technology is often depicted as an easy solution to achieve some type of information processing with tenuous if any link to strategic execution needed for business performance. Implementation failures and cost-and-time overruns that characterize many large-scale technology projects are directly attributable to this paradigm (Anthes and Hoffman, 2003; Strassmann, 2003). Often the missing link between technologies and business performance is attributable to choice of technologies intended to fix broken processes, business models, or organizational cultures. The practitioners influenced by this paradigm need to review the "lessons about processing" listed earlier in Table I.

The outcomes-driven paradigm of KM has its primary focus on business performance. Key emphasis is on strategic execution for driving selection and adaptation of processes and activities, and carefully selected technologies. For instance, if collaborative community activities do not contribute to the key customer value propositions or business value propositions of the enterprise, such activities are replaced with others that are more directly relevant to business performance (Malhotra, 2002a). If these activities are indeed relevant to business performance, then appropriate business models, processes, and culture are grown (Brooks, 1987) as a precursor to acceleration of their performance with the aid of KM technologies. Accordingly, emphasis on business performance outcomes as the key driver ensures that relevant processes and activities, as well as, related technologies are adopted, modified, rejected, replaced, or enhanced in service of business performance. The practitioners interested in this paradigm need to review the "lessons about outcomes" listed earlier in Table I.

The contrast between the outcomes-driven strategy-pull model and the input- and processing- driven technology-push model is even evident in the latest incarnation of KM 
under the moniker of RTE. Given the confusion between KM and KM technologies that resulted in the backlash against technology vendors, it is germane to point out a similar future for the proponents of RTE. There is an imperative need for making a clear distinction between the business performance capabilities afforded by the RTE business model and the technologies that are labeled as RTE technologies. As discussed earlier, success in strategic execution of a business process or business model may be accelerated with carefully chosen technologies. However, in absence of good business processes and business model, even the most sophisticated technologies cannot ensure corporate survival.

\section{Coming of the real time enterprise: the new knowledge management}

The RTE enterprise is based upon the premise of getting the right information to the right people at the right time (Gartner, Inc., 2002) in "real time", i.e. without latency or delay (cf., Lindorff, 2002; Lindquist, 2003; Margulius, 2002; Meyer, 2002; Siegele, 2002; Stewart, 2000). Enabling the RTE should lead to faster and better decisions, and enhanced agility and adaptability. RTE represents the future of knowledge enabled business processes: wherein digitized organizations interact with increasing and relentless speed and any specific "event" results in a real-time "response". For instance, businesses such as Gillette and Wal-Mart are trying to minimize the delay between a customer order, its shipment and the restocking of inventory with the help of radio-frequency detection (RFID) tags, also known as smart tags (Cuneo, 2003). The proponents of RTE technologies suggest that these technologies would help companies to learn to adapt, evolve, and survive within increasingly uncertain business environments. Their rationale still seems to be based on the technology-push model of KM and may perhaps benefit from recognizing the strategy-pull model as a complement. One such perspective of RTE (Khosla and Pal, 2002) that yet does not address Stewart's (2000) big question: "why?" and may benefit from focus proposed above is listed below:

Real time enterprises are organizations that enable automation of processes spanning different systems, media, and enterprise boundaries. Real time enterprises provide real time information to employees, customers, suppliers, and partners and implement processes to ensure that all information is current and consistent across all systems, minimizing batch and manual processes related to information. To achieve this, systems for a real time enterprise must be "adaptable" to change and accept "change as the process".

The RTE will be able to operate at speeds with split-second reaction times that may far exceed human speeds of gathering and processing of information, analysis, and response (Meyer, 2002). At least, that is what the proponents of "RTE technologies" such as Khosla and $\mathrm{Pal}$ (2002) claim. Examples of increase of business process velocity that are often attributed to information technology include the following examples (Gartner, Inc., 2002):

- trading analytics: from 30 minutes to five seconds;

- airline operations: from 20 minutes to 30 seconds;

- call center inquires: from eight hours to ten seconds;

- tracking finances: from one day to five minutes;

- supply chain updates: from one day to 15 minutes;

- phone activation: from three days to one hour;

- document transfer: from three days to 45 seconds;

- trade settlement: from five days to one day; and

- build-to-order PCs: from six weeks to one day.

RTE enterprises would harness everything from radio frequency sensors and smart dust to global positioning satellites and worker-monitoring software to monitor and control all processes and activities. There are obvious benefits of the automated event-driven architectures (Sliwa, 2003) for repetitive, structured, and routine decisions (Malhotra, 2004b). Well-tested business processes may be suitable candidates for acceleration with 
automation of manual activities and workflows (Malhotra, 2000d). However, the more critical problem can be understood in terms of the contrast between the technology-push model and the strategy-pull model. The programmed logic of the RTE may yield diminishing returns if environmental change outpaces the assumptions and logic embedded in its computerized networks. Split-second decisions based upon pre-determined "rules" are efficient as they follow the single-loop logic and are well suited to repetitive, structured, and routine decisions. However when such decisions are made regardless of the obsolescing business process or business model, the price is paid in terms of effectiveness (Drucker, 1994; Yuva, 2002). High-risk or high-return situations require reflection, and re-thinking as meaning of information could change and previously non-existent responses become feasible. This is all particularly applicable in contexts within which creativity and innovation facilitate emergence of new meaning, insights, and actions. Such complex meaning making and sense making capabilities for anticipating the unforeseen are yet unavailable in existing technologies (cf., Wolpert, 2001)[8].

\section{RTE business models: function should drive the choice of form}

Successful RTE enterprises focus primarily on the function of the business model that guides the choice of the infrastructure form for accelerating strategic execution. Unsuccessful RTE enterprises, in contrast, often meet their fate because of the misplaced belief that form could somehow compensate for the inadequacy of the function. Successful RTE business models may be apparent in virtual companies such as e-Bay that owe most of their functioning to social capital embedded in their users, buyers, and sellers. Successful RTE business models may also be apparent in companies with brick-and-mortar stores such as Wal-Mart. Regardless of the variations in form, most such companies share a similar but distinctive focus on their higher purpose, which guides their strategy and its execution. This observation perhaps explains how some companies achieved most sustained business performance with lesser investments in related technologies. Often their success was attributable to a differentiated business model based on strong ties with customers and suppliers rather than most recent investments in CRM and SCM systems. Strategic execution of the business models was accelerated with the help of technologies. However, successful companies had superior business models and a consistent track record of strategic execution as a precursor. Smart and selective investments in technologies afforded them the ability to do more with less by accelerating their business capabilities. Also, strong ties with suppliers and customers enabled them to spread the risk of investing, deploying, and utilizing the technologies with their partners and customers[9].

\section{Enabling the RTE: ends should drive the choice of means}

The misplaced emphasis of technology-push models arose from their primary focus on the means rather than the ends as explained in this section. Most such KM implementations often happened to be caught in the convoluted complexities of technology deployment and processing without making a real difference in business performance. Given the state of technology and the long time spans necessary for getting business systems in place, an obvious question is relevant about the superior business performers: how did the top performing companies manage to produce stellar business results despite having to choose same or similar technologies as their competitors? It may be argued that the top performers always kept their key focus on business performance. They adopted new technologies and adapted old technologies without compromising on that primary focus. Their technologies were used for pushing data, information, and decision models just like their competitors. However, unlike the competitors they vanquished, their choices of business processes and technologies were still driven by their primary focus on strategic execution. They may not have planned to be laggards in adopting new technologies or in spending less on such tech investments. Rather their slow but steady progress in selecting, eliminating, modifying, adapting, and integrating old and new technologies in service of their business models and business processes seemed to pay off. As they accelerated their already superior business models and business processes with new technologies, they realized greater returns in business performance. It may also be argued that many of their competitors imitated their choices of specific technologies often based upon "best practice" studies and 
"benchmarks" (Malhotra, 2002d). Mistakenly treated as easy and assured solutions for fixing broken business processes and business models, new technologies further escalated the "knowledge application gap". Some of these comparison companies saw a spate of fickle and frequent technology and tech personnel changes, but their business problems persisted eventually leading to corporate failures or bankruptcies. In contrast, top performing companies have grown their business models around carefully thought out customer value propositions and business value propositions in spite of their adoption, or lack thereof, of latest technologies. Knowledge becomes the accelerator of business performance when identified with execution of business strategy rather than with the choices of tools and technologies that keep changing with time. In the eyes of the wise, knowledge and action are one (Beer, 1994).

\section{Why do some RTE businesses succeed (where others fail)?}

The following cases were selected after reviewing the industry case studies of companies that were often described as benchmarks in terms of their RTE business models. Specific companies were chosen based on their visibility in the business technology press and popular media. The reviews of industry cases studies were guided by our interest in understanding the link between investments in advanced technologies and resulting business performance.

\section{Wal-Mart: RTE business model where technology matters less}

Some IT analysts have attributed Wal-Mart's success to its investment in RTE technologies. However, Wal-Mart has emerged as a company that has set the benchmark of doing more with less. Wal-Mart did not build its competitive advantage by investing heavily or by investing in latest technologies (Schrage, 2002). A McKinsey Global Institute reports:

The technology that went into what Wal-Mart did was not brand new and not especially at the technological frontiers, but when it was combined with the firm's managerial and organizational innovations, the impact was huge.

More recently, Collins (2003) has predicted that Wal-Mart may become the first company to achieve trillion-dollar valuation within next ten years following the performance-driven model delineated in Table I and discussed earlier. In contrast to its competitors, Wal-Mart systematically and rigorously deployed its technologies with clear focus on its core value proposition of lowest prices for mass consumers. With that singular focus, it went about setting up its supply chains and inventory management systems to accelerate business performance. Long before anyone had heard about the RTE technologies, Wal-Mart was perfecting its logistic prowess based on the hub-and-spoke model of truck routes and warehouses underlying its inventory management systems. It was much later in the process when for its $\$ 4$ billion investment in its supply chain systems its suppliers invested ten times that amount to accelerate its RTE business model underlying its supply chain network (Schrage, 2002). The business model created the strong linkages with suppliers, which not only heavily subsidized the costs of technology investments but also pre-committed the partners to the success of the shared systems. Simultaneously, given its retail channels, distribution network, and proximity to customers through market scanner data, it has preempted its suppliers from directly competing against it.

\section{Dell: RTE business model that does more with less}

Dell has developed and perfected its business model by developing strong ties with its customer base over the past 17 years. It perfected its business model over several years before accelerating its business performance with the aid of carefully selected technologies. It has cultivated outstanding relationships with its virtual supply chain partners including outsourcing providers (such as Solectron) and technology vendors (such as HP, Sony, and EMC). Dell also leverages its customer reach and range and market penetration for deriving commercial benefits from technologies developed by its technology partners. It has been developing and extending the real time logic over the past several years first for selling and servicing desktop computers, and later to aggregation and distribution of value-added products and services servers, storage, networking, printers, switches, and handheld 
computers. According to a survey of 7,500 companies conducted by Alinean (2002), Dell is a thrifty IT spender. Dell is equally frugal in its R\&D spending (1.5 percent of revenues), according to a recent Business Week report, despite its continuing forays into new products and services. Through its alliances with partners such as EMC, Dell is able to leverage their research on product innovation while itself concentrating on perfecting the linkages with customers as well as suppliers. Dell's early innovations in passionate pursuit for being the low cost "build on demand" leader for consumer computing products has yielded it the advantage of real time business performance. More recently, it has been able to accelerate the performance of its business model with the aid of carefully chosen technologies.

\section{GE: RTE automation for operational efficiencies}

GE views the real time movement as an extension of GE's renowned emphasis on Six Sigma quality drive. The business model defined for maintaining quality standards has been extended to control costs by minimizing response time to problems affecting products purchased by its customers. GE's CIO Gary Reiner tracks once every 15 minutes what he considers to be the few most critical variables including sales, daily order rates, inventory levels, and savings from automation across the company's 13 worldwide businesses. He acknowledges that it is neither feasible nor desirable to track all kinds of information in real time even with the aid of digital dashboards. Most operational information is tracked on daily or weekly basis while other kinds of information is tracked on an exception-reporting basis. The company claims operational savings of 35-60 percent in costs involved in customer response, customer service, and sales. Most of these savings are attributable more to management control rather than to technologies that are used to enforce pre-negotiated contracts on its buyers who deal with its various suppliers. Operational automation that is executed in terms of command and control logic seeking compliance has not been without its adverse ramifications. GE has encountered labor management disputes resulting from the workers who are not accustomed to minute-by-minute electronic surveillance.

\section{Cisco: real time enterprise technology troubles}

Cisco has been lauded for its RTE technologies since three years ago when its market cap was 850 percent of its recent market capitalization during this year. The company prided itself about the RTE technologies that offered apparently seamless integration of real time data within and across its supply chain and customer ordering systems. The company had legendary faith in its technologies for predictive modeling and decision-making (Carter, 2001). In a Harvard Business Review article, the company's CFO (of that time) claimed that:

We can literally close our books within hours ... the decision makers who need to achieve sales targets, manage expenses and make daily tactical operating decisions now have real-time access to detailed operating data.

Unfortunately, real-time access to data could not be of much help when, buoyed by its unparalleled growth over several quarters[10], Cisco made some fundamentally incorrect assumptions about the future. Cisco ignored a key lesson of KM that is often ignored by many others: the past may not be an accurate predictor of the future. While other networking companies with less sophisticated technologies had cut back on production schedules months earlier seeing impending downturn in demand, Cisco stuck to the forecasts of their "virtual close" system that they considered invincible. As Cisco (or, rather, its technology-driven forecasting systems) had never been proven wrong before, their business partners saw little merit in trying to question their proven wisdom. As a result of misplaced faith in the power of the forecasting systems, Cisco ended up writing off $\$ 2.2$ billion in inventories and sacking 8,500 employees. Industry experts and analysts suggest that Cisco's write-off resulted from its blindsided over-reliance on its much vaunted "virtual close" systems. Cisco's case demonstrates that even the best technology offers no protection against bad management decisions, especially when the assumptions embedded in the dominant logic are taken for granted. Some Cisco executives do maintain that in absence of the RTE "virtual close", the outcome could have been worse. Cisco retains its optimism in perfecting its RTE systems hoping they would eventually provide high certitude in the face of increasingly uncertain business environment. 


\section{Enron: destroyed in real time}

Given the dominant and intensive role of real-time information, many of the technologies associated with real-time response were initially adopted by financial services firms on the Wall Street. Given Enron Online's primary business of exchanging and trading financial data, the real-time response model seemed like a match made in heaven. Enron planned to leverage its online exchange for facilitating direct real time instantaneous transactions in the online trading of energy market commodities. In its communiqué submitted to the Federal Trade Commission, Enron had emphasized that:

Efficiency gains made possible by dynamic pricing and trading are especially well suited to Enron's on-line business because electronic trading can match the speed with which commodity pricing changes. Transactions that used to take up to three minutes to complete over the phone now take just a second or two, including complex processes such as credit checks.

The company deployed Tibco's vaunted "RTE platform", sought out new technology wherever possible, and planned to spend hundreds of millions of dollars on technology infrastructure. The management control and oversight vagaries of Enron's management as well its insider- and self-dealings with fictitious entities are well documented in the records of the US Senate hearings as well as the public records of print and broadcast media. Post-hoc analysis of Enron's RTE technologies confirms prior observations about the technology-push model (Berinato, 2002):

If these [accounting irregularities] hadn't come up, the IT inefficiency might well have come up to bite Enron ... Enron IT was as cutting edge as it was Byzantine. There were plenty of great tools, but there was precious little planning ... The core systems supporting the main revenue-generating activities were very disjointed ... There were major disconnects from deal capture to risk management to logistics to accounting. They all worked from different data sources ... They had teams and teams of people who had to comb through the data and massage it so that it made sense... There was a lot of magic, transforming apples into oranges and oranges into apples. Preparing annual reports was a joke... The breakneck deployment of state-of-the-art technology was done with little regard for a management plan.

When the cover about the collusion between Enron insiders and its auditing firm blew open, the RTE system triggered the freefall of Enron as it was also covering the risk exposure related to its instantaneous transactions. Unfounded and overly optimistic belief in technology as the means for generating profits despite an inadequate business model led to Enron's downfall resulting in one of the largest corporate bankruptcies in US history[11].

\section{Conclusion}

This article opened with the observation that although KM activities are "all over the map" in terms of technology implementations, however, no one has asked the "big question": why? Despite diverse propositions about "getting the right information to the right person at the right time," almost everyone neglects to ask what knowledge to manage and toward what end. A review of the industry case studies of companies characterized in the recent years as RTE business enterprises surfaced some interesting insights. Recent industry analyses that have demonstrated inverse correlations between IT investments and business performance provided some motivation for this analyses. Additional impetus was provided by the contrast between the hype about "RTE technologies" propagated by some IT analysts and our in-depth analysis of companies that achieved success as RTE benchmarks. To some extent the search for the "next big thing" and the "killer app" is to blame for its narrow focus on IT and innovation as ends rather than means for achieving sustainable business performance (Business Week, 2003). The big question "Why?" should drive tactical and operational aspects of technology and process related innovations in an organizational KM implementation. As contrasted with the inputs- and processing-focused technology-push model, explicit and specific performance outcomes oriented focus of the strategy-push model, further emphasized the focus on the "big question."

The contrast between the three archetypes of inputs-, processing-, and outputs-driven paradigms of KM explained in Table I and Table II further aided deconstruction of the existing conceptualizations and practices of KM. One such conceptualization of KM that has 
been applied in diverse worldwide governmental and corporate practices was then discussed to motivate subsequent discussion on the RTE business models. The contrast between information-processing capabilities of latest technologies and needed sense-making capabilities was then explained. Additionally, the mechanistic emphasis of technology-based linkages was contrasted with appreciation for organic and socio-psychological relationships needed for nurturing knowledge processes. Two propositions were offered based on prior discussion - one pertaining to the form and function of the RTE, and the second relevant to the contrast between ends and means of achieving performance outcomes. Based upon original analyses, review of prior research, and review of industry case studies we made specific managerial recommendations about realizing the real time performance of enterprise business models. Specifically, we recommended that:

- organizational function should drive the choice of organizational form; and

- ends should drive the choice of means.

The above propositions were then illustrated with the aid of RTE industry case studies that have been used by IT analysts to hype the benefits of RTE technologies. Based upon our analyses, we counter-argued that the benefits attributed to the RTE technologies should indeed be attributable to the RTE business model. We further contended that in absence of an effective RTE business model, even the most expensive and sophisticated technology could not ensure corporate survival in the short- or long-term. The RTE case studies lent support to the primary role of strategic execution as the lever for sustained business performance. As discussed, the successful RTE enterprises achieved their success by staying a step ahead of competition and by offering value propositions that inspired customers' imagination instead of playing the "me too" game in an already crowded market. These companies also selected and integrated ICT capabilities that fit directly with what they were deeply passionate about, what they believed they could be the best at, and what directly drove their steady economic growth. The successful RTE businesses did not adopt new technologies motivated by fear of getting behind. Rather, they thought differently about technology as an accelerator of business momentum and not its creator. Unlike the successful models of RTE enterprises, the failures were characterized by thoughtless reliance on technology often grasped as an easy solution, without coherent understanding of how it links to strategic execution for business performance.

\section{Background readings and research}

\section{KMNetwork: www.kmnetwork.com/}

The above portal provides unrestricted access to several full-text articles and research papers by the author that have preceded this milestone in fathoming the ongoing evolution and progress in the field of knowledge management.

There are several excellent reviews of various types of information and communication technologies (ICTs) that are used within the realms of KM applications. The focus of this article is on the strategic and overarching framework of real time enterprises and business performance within which specific ICTs are used. For more specifics on technologies that are relevant to the input and processing aspects of both $\mathrm{KM}$ models discussed herein, the reader is advised to peruse Tsui (2002); O'Leary (2002); Conway (2002); Gray and Tehrani (2002); Gray and Tehrani (2002); Susarla et al. (2002); Wei et al. (2002); and Jackson (2001).

\section{Notes}

1. Strassmann's research has primarily focused on macro-economic analysis of industry IT investments data and has not empirically studied the behavioral and strategic disconnects related to IT and KM performance discussed in this paper. Author's seminal research in this context - referenced in this article - specifically focuses on these disconnects between IT, information, actions, and performance at individual, organizational, and national levels. Therefore, author's research on behavioral-strategic disconnects between IT- and KM-performance complements research by others that has focused primarily on macro-economic aspects. An interesting focus for 
future practice and research is in terms of reconciling existing gaps between economic, sociological, and behavioral aspects of IT- and KM-performance as recommended in Malhotra (2003).

2. Some may argue that the interest in digitizing knowledge of business enterprises pre-dates 1990s as prior Al and expert systems have focused on such processes. Our focus in this article is on the "real-time enterprise" logic in which inter-connected value-chains can respond in real-time to supply and demand changes almost in real time. As the commercialization of the web occurred much later than the invention of the first browser version of Mosaic, such real-time capabilities of networking across enterprises were not available and as affordable in the post-1995 era. However, there are fundamental problems characterizing the $\mathrm{Al}$ and expert systems based focus on KM systems that is discussed in greater depth in the contrast between "sense making" and "information processing" capabilities explained in the Expert Systems With Applications journal special issue on knowledge management (Malhotra, 2001b).

3. This argument is supported by examples of technology pioneers of yesteryears that have faded into oblivion. For instance, Visicalc, the company that pioneered the spreadsheet lost out to Lotus 1-2-3 which itself lot out to Ms-Excel. The first portable computers came from Osborne, a company that ceased to exist long before portables became adopted by the mainstream.

4. The technology-push model and the strategy-pull model of KM implementation are discussed as contrasting "archetypes" for business environments ranging from highly routine and predictable environments to radically changing and discontinuous environments. It is, however, recognized that most real world business environments as well as most real world business contexts would fall between the two polar contrasts. Hence most such RTE models would effectively combine the two models for balancing new knowledge creation and commercial exploitation of existing knowledge. Balancing the two processes is discussed in author's interview with the Institute for supply management featured in the knowledge management cover story of inside supply management (Yuva, 2002). Additional discussion on balancing the apparently paradoxical processes is available in Malhotra (2000a, 2001a, 2002a).

5. For more details on single-loop and double-loop learning, the reader is advised to see seminal writings of Chris Argyris such as Argyris (1990) and Argyris (1994).

6. In some cases of technology implementation such as ERP, the issues of technology deployment and utilization could never get addressed, resulting in snowballing downslide of business performance (see for instance, Strassmann, 2003).

7. Such as the US Federal Government, United States Army, European Commission, US Agency for International Development, Government of UK, Government of South Africa, Parliament of Victoria (Australia), Government of New Zealand, Government of Argentina, SAP North America, Microsoft Europe, Verisign, Telecom Italia, Organization of Islamic Capitals and Cities (Saudi Arabia), and United Nations and its worldwide agencies. More details accessible at: www.brint.com/ casestudies.html

8. Additional discussion on how existing "information processing" focus of technology on semantics (meaning) has yet to address the "sense making" capacities of human beings within the context of the new paradigm of self-regulation and self-control is available in Malhotra (2001b, c, 2002b).

9. It is understandable that WS-I and related web service based experiments (such as RosettaNet) provide hope for technological feasibility of real-time information exchange. However, despite the exploitation of most sophisticated technical standards, information exchange within and between enterprises remain more of a sociological and cultural issue than a technical issue. Hence, despite availability of technical standards that may ensure perfect real time communication, sociological and cultural artifacts impose a major burden. Conversely, concerns that tend well to such sociological and cultural concerns, as discussed in this article, accelerate their RTE business models through adoption of facilitating technologies. More in-depth discussion on this theme is available in the author's Intel Corporation's e-strategy research paper (Malhotra, 2001a).

10. Growth consisted of 40 quarters of straight growth and three immediate quarters of extreme growth to the tune of 66 percent.

11. One news story had the following remarks about Enron's business model: "In the aftermath of the collapse, there have been suggestions that a few directors had mishandled the partnerships to siphon off funds to their own accounts. However, it is clear that the more than 3,000 partnerships, 
more than 800 of which were in tax havens like the Cayman Islands, played a far more purposeful role in Enron's business model." Despite real time availability of information, the corporate crisis in this case pertains to sociological and cultural issues such as senior management's corruption and auditors' dishonesty that led to "real time" cover-ups despite access to best technology.

\section{References}

Ackoff, R. (1979), "The future of operations research is past", Journal of the Operations Research Society, Vol. 30, p. 93.

Argyris, C. (1990), Integrating the Individual and the Organization, Transaction, New Brunswick, NJ.

Argyris, C. (1994), "Good communication that blocks learning", Harvard Business Review, Vol. 72 No. 4, pp. 77-85.

Alavi, M. and Leidner, D. (2001), "Review: knowledge management and knowledge management systems: conceptual foundations and research issues", MIS Quarterly, Vol. 25 No. 1, pp. 107-36.

Alinean (2002), "Alinean identifies why certain companies achieve higher ROI from IT investments", available at: www.alinean.com

Anthes, G.H. and Hoffman, T. (2003), "Tarnished image", Computerworld, May 12, pp. 37-40.

Arthur, B. (1996), "Increasing returns and the new world of business", Harvard Business Review, Vol. 74 No. 4, pp. 100-9.

Barth, S. (2000), "KM horror stories", Knowledge Management, Vol. 3 No. 10, pp. 36-40.

Beer, S. (1994), "May the whole earth be happy: Loka Samastat Sukhino Bhavantu", Interfaces, Vol. 24 No. 4, pp. 83-93.

Berinato, S. (2002), "Enron IT: a tale of excess and chaos", ClO Magazine, available at: www.cio.com/executive/edit/030502_enron.html

Brooks, F.P. Jr (1987), "No silver bullet: essence and accidents of software engineering", Computer, Vol. 20 No. 4, pp. 10-19.

Brynjolfsson, E. (1993), "The productivity paradox of information technology", Communications of the ACM, Vol. 36 No. 12, pp. 66-77.

Brynjolfsson, E. and Hitt, L.M. (1996), "Paradox lost? Firm-level evidence on the returns to information systems spending", Management Science, Vol. 42, pp. 541-58.

Brynjolfsson, E. and Hitt, L.M. (1998), "Beyond the productivity paradox: computers are the catalyst for bigger changes", Communications of the ACM, Vol. 41 No. 8, pp. 49-55.

Business Week (2003), "What you don't know about Dell”, Business Week, November 3, pp. 76-84.

Byrne, J.A. (1993), "The virtual corporation", Business Week, February 8, pp. 98-103.

Carr, N. (2003), "IT doesn't matter", Harvard Business Review, Vol. 81 No. 5, pp. 41-9.

Carter, L. (2001), "Cisco's virtual close", Harvard Business Review, April.

Charles, S.K. (2002), "Knowledge management lessons from the document trenches", Online, Vol. 26 No. 1, pp. 22-9.

Churchman, C.W. (1971), The Design of Inquiring Systems, Basic Books, New York, NY.

Collins, J. (2001), Good to Great: Why Some Companies Make the Leap and Others Don't, Harper-Business, New York, NY.

Collins, J. (2003), "Bigger, better, faster", Fast Company, available at: www.fastcompany.com/ magazine/71/walmart.html

Conway, S. (2002), "Knowledge searching and services", in Holsapple, C.W. (Ed.), Handbook on Knowledge Management 1: Knowledge Directions, Springer-Verlag, Heidelberg, pp. 69-84.

Cuneo, E.C. (2003), "Safe at sea", Information Week, April 7, available at: www.informationweek. com/story/showArticle.jhtml?articlelD = 8700375

Darrell, R., Reichheld, F.F. and Schefter, P. (2002), "Avoid the four perils of CRM", Harvard Business Review, February, pp. 101-9. 
Dragoon, A. (1995), "Knowledge management: Rx for success", ClO Magazine, Vol. 8 No. 18, pp. 48-56.

Drucker, P.F. (1994), "The theory of business", Harvard Business Review, September-October, pp. 95-104.

eMarketer (2001), "Knowledge management: executive brief", available at: www.info-edge.com/ samples/EM-2001free.pdf

Emery, F.E. and Trist, E.L. (1965), "The causal texture of organizational environments", Human Relations, Vol. 18, pp. 21-32.

Evans, P. and Wurster, T.S. (2002), Blown to Bits, Harvard Business School Press, Boston, MA.

Gartner, Inc. (2002), "The real time enterprise", available at: http://rte.gartner.com/

Gray, P. and Tehrani, S. (2002), "Technologies for disseminating knowledge”, in Holsapple, C.W. (Ed.), Handbook on Knowledge Management 1: Knowledge Directions, Springer-Verlag, Heidelberg, pp. 109-28.

Greenemeier, L. (2003a), "HP looks to utility computing for growth", Information Week, May 12, available at: www.informationweek.com/story/showArticle.jhtml?articlelD $=9800052$

Greenemeier, L. (2003b), "Utility computing meets real life", Information Week, April 21, available at: www.informationweek.com/story/showArticle.jhtml?articlelD $=8800357$

Grover, V. and Davenport, T.H. (2001), "General perspectives on knowledge management: fostering a research agenda", Journal of Management Information Systems, Vol. 18 No. 1, pp. 5-21.

Hammer, M. (1990), "Reengineering work: don't automate", Harvard Business Review, July, pp. 104-12.

Hansen, M.T. and Nohria, N. (1999), "What's your strategy for managing knowledge?", Harvard Business Review, March-April, pp. 106-16.

Hapgood, F. (2003), "Plug and pay", CIO Magazine, April 15, available at: www.cio.com/ archive/ 041503/plug.html

Hildebrand, C. (1999), "Intellectual capitalism: does KM=IT?", CIO Magazine, September 15, available at: www.cio.com/archive/enterprise/091599_ic_content.html

Hoffman, T. (2002), “"Frugal' IT investors top best-performer list", Computerworld, December 6, available at: www.computerworld.com/managementtopics/roi/story/0,10801,76468,00.html

Hoffman, T. (2003), "Survey points to continuing friction between business, IT", Computerworld, May 12, p. 10.

Holsapple, C.W. (2002), "Knowledge and its attributes", in Holsapple, C.W. (Ed.), Handbook on Knowledge Management 1: Knowledge Matters, Springer-Verlag, Heidelberg, pp. 165-88.

Holsapple, C.W. and Singh, M. (2001), "The knowledge chain model: activities for competitiveness", Expert Systems with Applications, Vol. 20 No. 1, pp. 77-98.

Hopper, M.D. (1990), "Rattling SABRE - new ways to compete on information", Harvard Business Review, May/June, pp. 118-25.

Huber, R.L. (1993), "'How Continental Bank outsourced its 'crown jewels"', Harvard Business Review, January/February, pp. 121-9.

Jackson, C. (2001), "Process to product: creating tools in knowledge management", in Malhotra, Y. (Ed.), Knowledge Management for Business Model Innovation, Idea Group Publishing, Hershey, PA, pp. 402-13.

Khosla, V. and Pal, M. (2002), "Real time enterprises: a continuous migration approach", March, available at: www.asera.com/technology/pdf/RTE-WHITEPAPER-PDF-VERSION.pdf

Kirkpatrick, T.A. (2003), "Complexity: how to stave off chaos", ClO Insight, February 1, available at: $\underline{\text { www.cioinsight.com/print_article/0,3668,a }}=\underline{\text { 37126,00.asp }}$

Koenig, M.D. and Srikantaiah, T.K. (2000a), "The evolution of knowledge management", in Srikantaiah, K. and Koenig, M.E.D. (Eds), Knowledge Management for the Information Professional, Information Today Inc., Medford, NJ, pp. 37-61. 
Kraemer, K. (2001), "The productivity paradox: is it resolved? Is there a new one? What does it all mean for managers?", working paper, Center for Research on Information Technology and Organizations, UC Irvine, Irvine, CA.

LeClaire, J. and Cooper, L. (2000), "Rapid-Fire IT Infrastructure", Information Week, January 31, available at: www.informationweek.com/771/infrastruct.htm

Levitt, J. (2001), "Plug-and-play redefined", Information Week, April 2, available at: www.informationweek.com/831/web.htm

Lindorff, D. (2002), "GE's drive to real-time measurement", ClO Insight, November 11, available at: www.cioinsight.com/article2/0,3959,686147,00.asp

Lindquist, C. (2003), "What time is real time?", ClO Magazine, February 10, available at: www.cio.com/online/techtact_021003.html

Malhotra, Y. (1993), "Role of information technology in managing organizational change and organizational interdependence", BRINT Institute, LLC, New York, NY, available at: www.brint.com/ papers/change/

Malhotra, Y. (1995), "IS productivity and outsourcing policy: a conceptual framework and empirical analysis", Proceedings of Inaugural Americas Conference on Information Systems (Managerial Papers), Pittsburgh, PA, August 25-27, available at: www.brint.com/papers/outsourc/

Malhotra, Y. (1996), "Enterprise architecture: an overview", BRINT Institute, LLC, New York, NY, available at: www.brint.com/papers/enterarch.htm

Malhotra, Y. (1997), "Knowledge management in inquiring organizations", Proceedings of 3rd Americas Conference on Information Systems (Philosophy of Information Systems Mini-track), Indianapolis, IN, August 15-17, pp. 293-5, available at: www.kmnetwork.com/km.htm

Malhotra, Y. (1998a), "Role of social influence, self-determination, and quality of use in information technology acceptance and utilization: a theoretical framework and empirical field study", PhD thesis, Katz Graduate School of Business, University of Pittsburgh, Pittsburgh, PA.

Malhotra, Y. (1998b), "Knowledge management for the new world of business", Journal for Quality \& Participation, Vol. 21 No. 4, pp. 58-60.

Malhotra, Y. (1998c), "Knowledge management, knowledge organizations and knowledge workers: a view from the front lines", Maeil Business Newspaper, February 19, available at: www.brint.com/ interview/maeil.htm

Malhotra, Y. (2000a), "From information management to knowledge management: beyond the "hi-tech hidebound' systems", in Srikantaiah, K. and Koenig, M.E.D. (Eds), Knowledge Management for the Information Professional, Information Today Inc., Medford, NJ, pp. 37-61, available at: www.brint.org/IMtoKM.pdf

Malhotra, Y. (2000b), "Knowledge assets in the global economy: assessment of national intellectual capital", Journal of Global Information Management, Vol. 8 No. 3, pp. 5-15, available at: www.kmnetwork.com/intellectualcapital.htm

Malhotra, Y. (2000c), "Knowledge management and new organization forms: a framework for business model innovation", Information Resources Management Journal, Vol. 13 No. 1, pp. 5-14, available at: www.brint.org/KMNewOrg.pdf

Malhotra, Y. (2000d), "Knowledge management for e-business performance: advancing information strategy to 'internet time"', Information Strategy: The Executive's Journal, Vol. 16 No. 4, pp. 5-16, available at: www.brint.com/papers/kmebiz/kmebiz.html

Malhotra, Y. (2001a), "Enabling next generation e-business architectures: balancing integration and flexibility for managing business transformation", Intel e-Strategy White Paper, June, available at: www.brint.net/members/01060524/intelebusiness.pdf

Malhotra, Y. (2001b), "Expert systems for knowledge management: crossing the chasm between information processing and sense making", Expert Systems with Applications, Vol. 20 No. 1, pp. 7-16, available at: www.brint.org/expertsystems.pdf

Malhotra, Y. (2001c), "Organizational controls as enablers and constraints in successful knowledge management systems implementation", in Malhotra, Y. (Ed.), Knowledge Management and Business 
Model Innovation, Idea Group Publishing, Hershey, PA, pp. 326-36, available at: www.brint.org/ KMOutOfControl.pdf

Malhotra, Y. (2002a), "Enabling knowledge exchanges for e-business communities", Information Strategy: The Executive's Journal, Vol. 18 No. 3, pp. 26-31, available at: www.brint.org/ KnowledgeExchanges.pdf

Malhotra, Y. (2002b), "Information ecology and knowledge management: toward knowledge ecology for hyperturbulent organizational environments", Encyclopedia of Life Support Systems (EOLSS), UNESCO/Eolss Publishers, Oxford, available at: www.brint.org/KMEcology.pdf

Malhotra, Y. (2002c), "Is knowledge management really an oxymoron? Unraveling the role of organizational controls in knowledge management", in White, D. (Ed.), Knowledge Mapping and Management, Idea Group Publishing, Hershey, PA, pp. 1-13, available at: www.brint.org/KMOxymoron.pdf

Malhotra, Y. (2002d), "When best becomes worst", Momentum: The Quality Magazine of Australasia (Quality Society of Australasia), September, available at: www.brint.org/ bestpractices.pdf

Malhotra, Y. (2003), "Measuring national knowledge assets of a nation: knowledge systems for development (expert background paper)", Expanding Public Space for the Development of the Knowledge Society: Report of the Ad Hoc Expert Group Meeting on Knowledge Systems for Development, 4-5 September, Department of Economic and Social Affairs Division for Public Administration and Development Management, United Nations, New York, pp. 68-126, available at: www.kmnetwork.com/KnowledgeManagementMeasurementResearch.pdf; http://unpan1.un.org/ intradoc/groups/public/documents/un/unpan011601.pdf; http://unpan1.un.org/intradoc/groups/public/ documents/un/unpan014138.pdf

Malhotra, Y. (2004a), "Desperately seeking self-determination: key to the new enterprise logic of customer relationships", Proceedings of the Americas Conference on Information Systems (Process Automation and Management Track: Customer Relationship Management Mini-track), New York, NY, August 5-8.

Malhotra, Y. (2004b), "Why knowledge management systems fail. Enablers and constraints of knowledge management in human enterprises", in Koenig, M.E.D. and Srikantaiah, T.K. (Eds), Knowledge Management Lessons Learned: What Works and What Doesn't, Information Today Inc., Medford, NJ, pp. 87-112, available at: www.brint.org/WhyKMSFail.htm

Malhotra, Y. and Galletta, D.F. (1999), "Extending the technology acceptance model to account for social influence: theoretical bases and empirical validation", Proceedings of the Hawaii International Conference on System Sciences (HICSS 32), pp. 6-19, available at: www.brint.org/technologyacceptance.pdf

Malhotra, Y. and Galletta, D.F. (2003), "Role of commitment and motivation in knowledge management systems implementation: theory, conceptualization, and measurement of antecedents of success", Proceedings of the Hawaii International Conference on Systems Sciences (HICSS 36), available at: www.brint.org/KMSuccess.pdf

Malhotra, Y. and Galletta, D.F. (n.d.a), "A multidimensional commitment model of knowledge management systems acceptance and use", Journal of Management Information Systems (in press).

Malhotra, Y. and Galletta, D.F. (n.d.b), "If you build IT, and they come: building systems that users want to use", Communications of the ACM (in press).

Margulius, D.L. (2002), "Dawn of the real-time enterprise", InfoWorld, January 17, available at: www.infoworld.com/article/02/01/17/020121fetca_1.html

Massey, A.P., Montoya-Weiss, M.M. and Holcom, K. (2001), "Re-engineering the customer relationship: leveraging knowledge assets at IBM", Decision Support Systems, Vol. 32 No. 2, pp. 155-70.

Meyer, C. (2002), "Keeping pace with the accelerating enterprise", CIO Insight, November 2, available at: www.cioinsight.com/article2/0,3959,675333,00.asp

Murphy, C. (2003), "Tying it all together", Information Week, March 17, available at: www.informationweek.com/shared/printableArticle.jhtml?articleID $=8700225$

Nadler, D.A. and Shaw, R.B. (1995), "Change leadership: core competency for the twenty-first century", in Nadler, D.A., Shaw, R.B. and Walton, A.E. (Eds), Discontinuous Change: Leading Organizational Transformation, Jossey-Bass, San Francisco, CA. 
Nonaka, I. and Takeuchi, H. (1995), The Knowledge-Creating Company, Oxford University Press, New York, NY.

Odom, C. and Starns, J. (2003), "KM technologies assessment", KM World, May, pp. 18-28.

O'Leary, D. (2002), "Technologies of knowledge storage and assimilation”, in Holsapple, C.W. (Ed.), Handbook on Knowledge Management 1: Knowledge Directions, Springer-Verlag, Heidelberg, pp. 29-46.

Porter, M.E. and Millar, V.E. (1985), "How information technology gives you competitive advantage", Harvard Business Review, Vol. 63 No. 4, pp. 149-60.

Rayport, J.F. and Sviokla, J.J. (1995), "Exploiting the virtual value chain", Harvard Business Review, Vol. 73 No. 6, pp. 75-99.

Sawhney, M. (2003), "Reality check", ClO Magazine, March 1, available at: www.cio.com/ archive/030103/netgains.html

Schrage, M. (2002), "Wal-Mart trumps Moore's law", Technology Review, Vol. 105 No. 2, p. 21.

Schultze, U. and Leidner, D. (2002), "Studying knowledge management in information systems resarch: discourses and theoretical assumptions", MIS Quarterly, Vol. 26 No. 3, pp. 213-42.

Siegele, L. (2002), "The real-time economy: how about now?", CFO (The Economist), February 1, available at: www.cfo.com/printarticle/0,5317,6651\%7C,00.html

Sliwa, C. (2003), "Event-driven architecture poised for wide adoption", Computerworld, May 12, p. 8.

Stewart, T.A. (2000), "How Cisco and Alcoa make real time work", Fortune, May 29.

Stewart, T.A. and Kaufman, D.C. (1995), "Getting real about brainpower", Fortune, December 11.

Strassmann, P. (1997), The Squandered Computer: Evaluating the Business Alignment of Information Technologies, Information Economics Press, New Canaan, CT.

Strassmann, P. (2003), "Enterprise software's end", Computerworld, May 12, p. 35.

Susarla, A., Liu, D. and Whinston, A.B. (2002), "Peer-to-peer knowledge management”, in Holsapple, C.W. (Ed.), Handbook on Knowledge Management 1: Knowledge Directions, Springer-Verlag, Heidelberg, pp. $129-40$.

Terreberry, S. (1968), "The evolution of organizational environments", Administrative Science Quarterly, Vol. 12, pp. 590-613.

Thickins, G. (2003), "Utility computing: the next new IT model", Darwin Magazine, April, available at: www.darwinmag.com/read/040103/utility.html

Tsui, E. (2002), "Tracking the role and evolution of commercial knowledge management software", in Holsapple, C.W. (Ed.), Handbook on Knowledge Management 1: Knowledge Directions, Springer-Verlag, Heidelberg, pp. 5-27.

Verton, D. (2002), "Insiders slam navy intranet", Computerworld, May 27, pp. 1-16.

Wei, C., Piramuthu, S. and Shaw, M.J. (2002), "Knowledge discovery and data mining", in Holsapple, C.W. (Ed.), Handbook on Knowledge Management 1: Knowledge Directions, Springer-Verlag, Heidelberg, pp. 157-92.

Wolpert, D.H. (2001), "Computational capabilities of physical systems", Physical Review E, Vol. 65 No. 1, pp. 1-27, available at: www.santafe.edu/sfi/publications/Working-Papers/96-03-008.pdf

Yuva, J. (2002), "Knowledge management - the supply chain nerve center", Inside Supply Management, Institute for Supply Management, July, pp. 34-43, available at: www.brint.org/ KnowledgeManagementTheSupplyChainNerveCenter.pdf

Zack, M.H. (2001), "If managing knowledge is the solution, then what's the problem?", in Malhotra, Y. (Ed.), Knowledge Management and Business Model Innovation, Idea Group Publishing, Hershey, PA.

Zetie, C. (2003), "Machine-to-machine integration: the next big thing?", Information Week, April 14, available at: www.informationweek.com/story/showArticle.jhtml?articlelD $=8900042$ 